
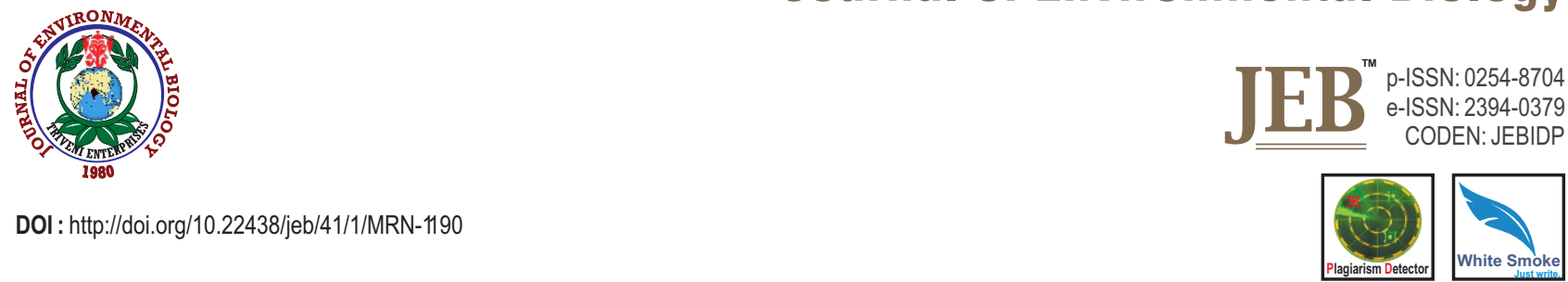

\title{
Studies on the development of cassava based reconstituted dry starch sago with modified starch as binder and characterization of its physico-functional properties
}

\author{
T. Krishnakumar', M.S. Sajeev', S. Raju', N.A. Giri', C. Pradeepika' and V. Bansode ${ }^{1}$ \\ ${ }^{1}$ Division of Crop Utilization, ICAR-Central Tuber Crops Research Institute (CTCRI), Thiruvananthapuram-695 017, India \\ ${ }^{2}$ Regional Centre, ICAR-Central Tuber Crops Research Institute (CTCRI), Bhubaneswar-751 019, India \\ *Corresponding Author Email : krishnakumar.t@icar.gov.in
}

\section{Abstract}

Aim : The objective of the study was to develop and characterize the properties of sago (sabudana) from cassava based reconstituted dry starch with addition of pre-gelatinized starch and wet starch as binders.

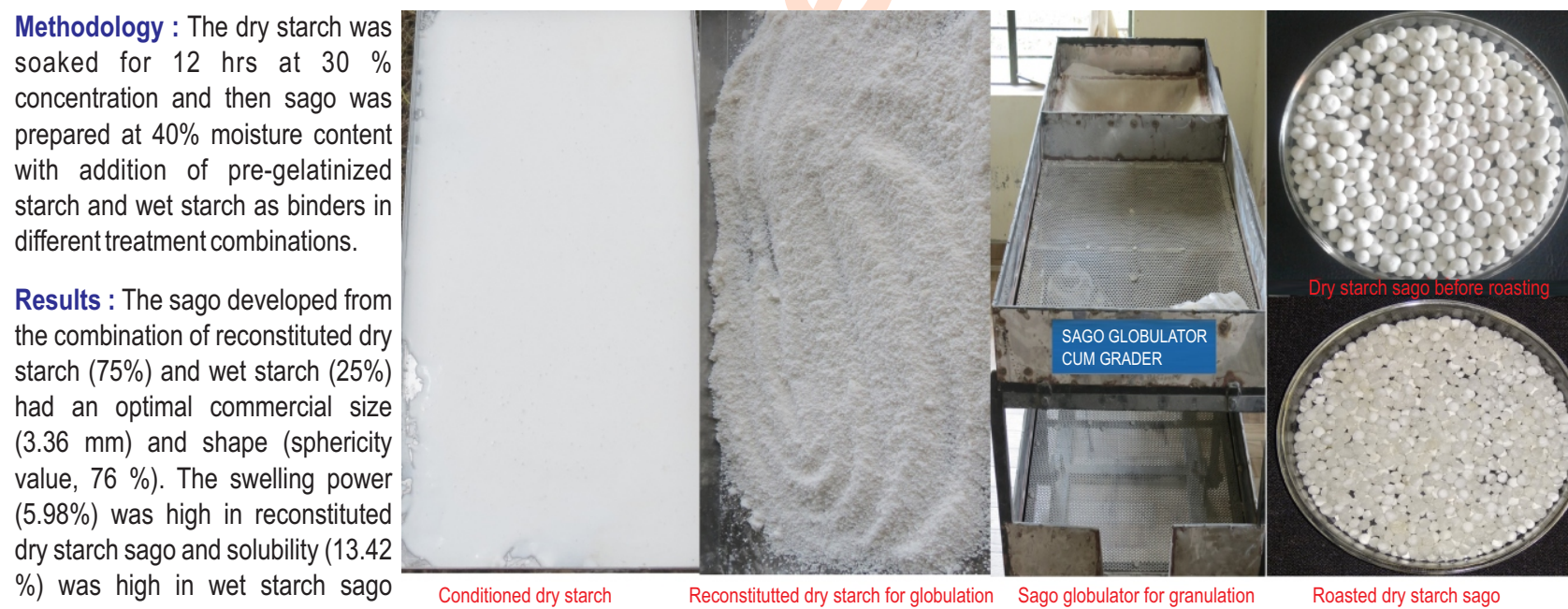
without the addition of any binders.

The increase in cooking time (10.37\%) and decrease in cooking loss (1.73\%) were observed for sago developed with pre-gelatinized starch as binder. The lowest oil absorption index $\left(0.45 \mathrm{~g} \mathrm{~g}^{-1}\right)$ was noticed for sago prepared with wet starch as a binder. The storage modulus was comparatively lower for sago paste prepared using wet starch and thus the sago gel behaved like a dilute solution with increase in storage modulus and phase angle.

Interpretation : The physico-functional properties of the cassava -based reconstituted dry starch sago can be improved by adding wet starch as a binder due to less retrogradation rate. Further, the addition of pre-gelatinized starch as a binder with reconstituted cassava dry starch can reduce the cooking loss in sago.

Key words: Binders, Cassava, Reconstituted dry starch sago, Roasting, Wet starch

How to cite : Krishnakumar, T., M.S. Sajeev, S. Raju, N.A. Giri, C. Pradeepika and V. Bansode: Studies on the development of cassava based reconstituted dry starch sago with modified starch as binder and characterization of its physico-functional properties. J. Environ. Biol., 41, 29-34 (2020). 


\section{Introduction}

Cassava (Manihot esculenta Crantz) occupies the first position in the world in terms of area and production among the tropical tuber crops. It is considered as poor man's crop and is a staple food for millions of people in the tropical countries. It is one of the major tuber crops cultivated in India having an area of 0.20 million hectares with a total production of 4.34 million tonnes (Krishnakumar and Sajeev, 2018). It is a good source of minerals such as calcium, iron, magnesium and phosphorus and carries high calorific value compared to other tubers such as yam, potato and sweet potato (Krishnakumar and Sajeev, 2017).

Sago (sabudana) or Tapioca pearl is a product made from wet starch obtained from fresh cassava roots. It is a processed, easily digestible, edible starch marketed in the form of small globules. In India, sago is manufactured only from the fresh wet cassava starch (Balagopalan et al., 1988; BIS, 1971). It is a popular food during festive seasons in many parts of India. It is used for preparing food item called "Khichadi" in Maharastra and Madhya Pradesh and used as baby food in West Bengal. It is highly recommended for patients due to energy rich (350 Kcal) and easily digestible food (Vijayakumari Asha et al., 2014). Sago is commercially classified into two types viz. roasted sago (Commercial sago) and steamed sago (Nylon sago).

The process of sago production consists of several unit operations such as washing, peeling, crushing, settling, powdering, sizing, roasting or steaming, drying and polishing (Sajeev et al., 2012). The harvesting of cassava tubers is seasonal (October to February) in India. During peak processing periods, most factories have insufficient preparation and capacity to process the extracted starch into sago (Nanda and Kurup, 1994; Sajeev and Balagopalan, 2005). The surplus or unutilized fresh cassava wet starch is transferred into open concrete tanks for 3 to 4 months with adequate quantities of water (Sajeev et al., 2012), then dug out at the end of season, re-washed and processed as fresh starch (Jyothi et al., 2007).

The long-term storage of cassava wet starch under wet condition results in weight loss and leads into a number of quality changes such as reduction in viscosity, optical clarity and discolouration and unpleasant odour of starch paste (George et al.,1995; Jyothi et al., 2007). The water requirement is relatively high for wet starch based sago production (Sheriff et al., 2005). It requires $5000 \mathrm{I}$ of water to produce $200 \mathrm{~kg}$ of sago from 1 tonne of fresh cassava tubers. The low binding ability of reconstituted dry starch affects granule formation during globulation to some extent. No published literature is available for the production of sago from cassava based reconstituted dry starch. Pregelatinized starch has high binding ability due to high porosity, high toughness and increased particle surface area (Alebiowu and Itiola, 2002). Hence, the present study was attempted to develop sago from cassava based reconstituted dry starch in combination with pre-gelatinized starch and wet starch as binders to improve the binding ability of starch for sago preparation.

\section{Materials and Methods}

Raw material: The matured high yielding hybrid cassava variety, H-165 grown for 9 months at the ICAR-CTCRI institute research farm, Sreekariyam, Thiruvananthapuram, Kerala was used for the extraction of starch.

Preparation of starch: The standard procedure was adopted for cassava starch extraction according to Krishnakumar and Sajeev (2018). The fresh cassava tubers were peeled (skin and rind) and cut into small pieces using a motor operated chipping machine, then crushed in a mobile type starch extraction unit with adequate quantities of water. The crushed starch milk was then passed through $150 \mu \mathrm{m}$ (100 mesh) sieve and the resultant cassava starch milk was allowed to settle in a sedimentation tank for overnight. The settled cassava wet starch from sedimentation tank was then washed with excess water for at least three times to obtain bright white colour and further used for study purpose. A portion of wet starch was then dried in hot air oven at $50^{\circ} \mathrm{C}$ for 12 hrs and utilized for sago preparation with moisture content ranging from $12-14 \%$.

Conditioning of starch: For proper sago globulation, starch should possess an optimum moisture content of $40 \%$ moisture content. To obtain optimal moisture content (40\% w.b) of dry starch, a study was performed with different settling time (12, 24, $36,48 \mathrm{hr}$ ) and concentration (10, 20, 30, 40, 40,60\% w/v). Based on the optimization study, the desired settling time (12 hr) and concentration (30\%) were selected for sago preparation.

Experimental design and preparation of sago: To improve the binding ability of the reconstituted dry starch, pre-gelatinized cassava starch and wet starch were added as binders during sago preparation. The primary role of binders is to provide cohesiveness that is important for binding of solid starch particles under compaction to form sago. Pre-gelatinized starch was prepared using starch and water (1:2 ratio) by double plate method and added for sago preparation in different levels viz., 1 $\%, 3 \%$ and $5 \%$ (w/w basis). The different treatment combinations selected for the study were as follows: $T_{1}-100 \%$ wet starch; $T_{2}$ $100 \%$ reconstituted dry starch; $T_{3}-25 \%$ reconstituted dry starch + $75 \%$ wet starch; $\mathrm{T}_{4}-50 \%$ reconstituted dry starch $+50 \%$ wet starch; $\mathrm{T}_{5}-75 \%$ reconstituted dry starch $+25 \%$ wet starch; $\mathrm{T}_{6}-99$ $\%$ reconstituted dry starch $+1 \%$ pre-gelatinized starch; $\mathrm{T}_{7}-97 \%$ reconstituted dry starch $+3 \%$ pre-gelatinized starch; $\mathrm{T}_{8}-95 \%$ reconstituted dry starch $+5 \%$ pre-gelatinized starch.

The conditioned starches were powdered using spike mill and fed into globulator for globule formation. During globulation, the conditioned starch was subject to a process of building up and consolidation, which gives them the spherical shape. The oscillatory movement enables the starch granules to adhere together and form into globules after $15 \mathrm{~min}$. The roasting was carried out manually for $5 \mathrm{~min}$ at $200 \pm 2^{\circ} \mathrm{C}$ by applying $5 \mathrm{ml}$ of vegetable oil on a shallow metal pan made of mild steel sheet to gelatinize the surface of starch globules to retain the shape. The 
sago samples were then sun dried and used for experimental purpose with safe moisture content level (11\% d.b).

Physical properties: Sago samples were tested for physical properties such as size, moisture content, sphericity, bulk density, particle density and porosity. The dimensions; length $(\mathrm{L})$, width (W) and thickness (T) of sago samples were measured using digital vernier caliper (Make: Aerospace) with an accuracy of 0.01 $\mathrm{mm}$. The size of the sago samples were measured in terms of geometric mean diameter (Mohsenin, 1986). The moisture content of sago samples was determined using standard oven by placing $3 \mathrm{~g}$ of sample in a cup at $105^{\circ} \mathrm{C}$ for $3 \mathrm{hrs}$. The per centage $(\%)$ of moisture present in the sample was determined by calculating the difference in weight of the sample (AOAC, 1999). The shape of sago was expressed in terms of sphericity $(\phi)$ and defined as ratio of the surface area of the sphere having same volume as that of the grain to the surface area of the grain (Mohsenin, 1986). Bulk density $\mathrm{\rho b}\left(\mathrm{kg} \cdot \mathrm{m}^{-3}\right)$ was calculated by weighing the mass of material inserted into a cylinder with known volume. Particle density $\rho p\left(\mathrm{~kg} \cdot \mathrm{m}^{-3}\right)$ was estimated by pycnometer method (BLAUBRAND, Wertheim, Germany) with an inside volume of $0.516 \mathrm{~m}^{3}$ (Mohsenin, 1986). In this experiment, toluene was used as non water-soluble liquid. The ambient temperature $\left(28^{\circ} \mathrm{C}\right)$, density of toluene was noted as 867 $\mathrm{kg} \cdot \mathrm{m}^{-3}$. Porosity was calculated from the bulk and particle density of sago sample (Mohsenin, 1986).

Functional properties: Functional properties such as solubility index, swelling power, oil absorption index, pasting and rheological properties were measured for sago samples. Solubility index (\%) of cassava starch was determined following the method of Ding et al. (2006). A $2.5 \mathrm{~g}$ of cassava starch was weighed into $50 \mathrm{ml}$ centrifuge tube and heated in $30 \mathrm{ml}$ distilled water in a water bath at $60^{\circ} \mathrm{C}$ for 30 min without mixing and then centrifuged at $3000 \mathrm{rpm}$ for $10 \mathrm{~min}$. The supernatant was dried at $105^{\circ} \mathrm{C}$ to constant weight and the weight of dry solids were measured. Swelling power $(\mathrm{g} / \mathrm{g})$ was determined by the modified method of Betancur et al. (2001). A $2.5 \mathrm{~g}$ of sago sample was weighed into $50 \mathrm{ml}$ centrifuge tube and then $30 \mathrm{ml}$ of distilled water was added and mixed gently. The sample was heated in a water bath at $60^{\circ} \mathrm{C}$ for 30 min and centrifuged at $3000 \mathrm{rpm}$ for 10 min. The supernatant was decanted immediately after centrifuging. The weight of the sediment was taken and recorded. Cooking properties of sago were evaluated for optimal cooking time (OCT). Optimum cooking time (OCT) of sago sample was determined as per the approved method (66-50, AACC, 2000) corresponding to the disappearance of white core of sago with softness. To evaluate optimum cooking time (OCT), $10 \mathrm{~g}$ of sago was cooked in $300 \mathrm{ml}$ of distilled water. Cooking loss (\%), is the amount of solid residue in cooking water was determined by evaporating the cooking water in a convective hot air oven at $105^{\circ} \mathrm{C}$ for $16 \mathrm{hrs}$ (AACC, 2000).

The weight of residue was expressed as per centage of original sago sample (Debbous and Doctkott, 1999). Oil absorption index (OAI) of sago samples was determined by the method of Liadakis et al. (1993). Sunflower oil (5 ml) was added to $0.5 \mathrm{~g}$ of ground sample in a $15 \mathrm{ml}$ graduated glass centrifuge tube.
The sample was agitated on a vortex mixer for $1 \mathrm{~min}$ and allowed to stand at room temperature for $30 \mathrm{~min}$. The contents were centrifuged at $3000 \mathrm{xg}$ for $20 \mathrm{~min}$ and the volume of free oil was noted. All the experiments were carried out in triplicate.

Pasting properties of sago: Viscosity of sago samples was determined using a rapid visco analyzer (RVA-4, Newport Scientific, and Warriewood, Australia). The powdered sago sample ( $2.5 \mathrm{~g}$ dry weight) was accurately weighed into the aluminum canister and distilled water $(25 \mathrm{~g})$ was added and mixed well. The canister was placed in the RVA unit and the heating/cooling cycle was performed as per standard procedure. The slurry was heated from 50 to $95^{\circ} \mathrm{C}$ at $12^{\circ} \mathrm{C} / \mathrm{min}$ and held at $95^{\circ} \mathrm{C}$ for $2 \mathrm{~min}$. The paste was cooled to $50^{\circ} \mathrm{C}$ at $12^{\circ} \mathrm{C} / \mathrm{min}$ and finally maintained at $50^{\circ} \mathrm{C}$ for $2 \mathrm{~min}$. The parameters such as peak viscosity, breakdown viscosity, setback viscosity in terms of centipoises $(\mathrm{cP})$ and pasting temperature $\left({ }^{\circ} \mathrm{C}\right)$ were measured. In addition, setback viscosity (final - trough viscosity), disintegration rate, $(\%$ ratio of breakdown to peak viscosity) and retrogradation rate, ( $\%$ ratio of setback to peak viscosity) were also calculated.

Dynamic rheological properties of sago: In dynamic oscillation measurements, the potential energy dissipated as heat is separated into storage modulus and loss modulus. Storage dynamic modulus $\left(G^{\prime}\right)$ is a measure of the energy stored in the material and recovered from it per cycle while the loss modulus $\left(G^{\prime \prime}\right)$ is a measure of the energy dissipated or lost per cycle of sinusoidal deformation (Ferry, 1980). The ratio of energy lost to energy stored for each cycle defined as $\tan \delta$, which is indicating the physical behaviour of a system. In dynamic oscillation measurements, the frequency sweep of the two moduli ( $G^{\prime}$ and $G$ "), used to distinguish between the elastic and viscous properties of a material over a spectrum of times. When the viscous properties dominate, $G$ " exceeds $G^{\prime}$, and vice versa $\left(G^{\prime}>G^{\prime \prime}\right)$ when the elastic properties prevail. The dynamic rheological properties (storage modulus, loss modulus and phase angle) for the $10 \%(\mathrm{w} / \mathrm{v}) \mathrm{gel}$ suspension of the sago samples obtained from RVA studies were determined using Rheoplus MCR 51 Rheometer (M/s Anton Paar $\mathrm{GmbH}$. Germany) at $30^{\circ} \mathrm{C}$, using a parallel plate geometry system (PP20-SN5912, $1 \mathrm{~mm}$ diameter) at $1 \mathrm{~mm}$ gap. The following experimental conditions were selected: frequency 1 to $10 \mathrm{~Hz}$; strain of 1 per cent (\%). For each treatment, storage modulus ( $\left.G^{\prime}\right)$, loss modulus $\left(G^{\prime \prime}\right)$ and phase angle $(\delta)$ were recorded and the measurements were conducted in duplicates.

Statistical analyses: Data analyses was performed using $R$ software. A completely randomized design (factorial) was applied for analysis. Analysis of variance (ANOVA) and pairwise mean comparison were performed using Tukey's test to determine the significant effect of the independent variables. The treatments and their interactions were compared at $\mathrm{P}<0.05$ level.

\section{Results and Discussion}

Analysis of data showed that there was a significant difference between moisture content in all treatments, except $T_{2}$ 
Table 1: Physical properties of reconstituted cassava dry starch sago

\begin{tabular}{|c|c|c|c|c|c|c|c|c|}
\hline $\begin{array}{l}\text { Physical } \\
\text { properties }\end{array}$ & $\mathrm{T}_{1}$ & $\mathrm{~T}_{2}$ & $\mathrm{~T}_{3}$ & $\mathrm{~T}_{4}$ & $\mathrm{~T}_{5}$ & $\mathrm{~T}_{6}$ & $\mathrm{~T}_{7}$ & $\mathrm{~T}_{8}$ \\
\hline $\begin{array}{l}\text { Moisture } \\
\text { content } \\
(\%) \text { d.b }\end{array}$ & $11.5 \pm 0.01^{\mathrm{a}}$ & $12.4 \pm 0.12^{c}$ & $14.6 \pm 0.03^{f}$ & $15.5 \pm 0.01^{9}$ & $12.7 \pm 0.04^{e}$ & $12.4 \pm 0.03^{c}$ & $12.3 \pm 0.02^{b}$ & $12.6 \pm 0.04^{d}$ \\
\hline Size $(\mathrm{mm})$ & $3.52 \pm 0.11^{f}$ & $2.86 \pm 0.21^{b}$ & $3.15 \pm 0.91^{c}$ & $3.24 \pm 0.39^{d}$ & $3.36 \pm 0.25^{e}$ & $2.85 \pm 0.29^{a}$ & $2.86 \pm 0.36^{b}$ & $2.85 \pm 0.08^{\mathrm{a}}$ \\
\hline $\begin{array}{l}\text { Sphericity } \\
(\%)\end{array}$ & $78 \pm 1.37^{f}$ & $64 \pm 1.12^{b}$ & $66 \pm 1.65^{\circ}$ & $70 \pm 1.11^{d}$ & $73 \pm 1.57^{\circ}$ & $62 \pm 1.92^{\mathrm{a}}$ & $64 \pm 1.38^{b}$ & $62 \pm 1.82^{\mathrm{a}}$ \\
\hline $\begin{array}{l}\text { Bulk density } \\
\left(\mathrm{kg} \mathrm{m}^{3}\right)\end{array}$ & $510.53 \pm 0.29^{h}$ & $468.90 \pm 0.11^{e}$ & $441.44 \pm 0.18^{b}$ & $445.62 \pm 0.24^{c}$ & $465.02 \pm 0.13^{d}$ & $478.25 \pm 0.24^{\dagger}$ & $507.13 \pm 0.13^{9}$ & $425.21 \pm 0.21^{a}$ \\
\hline $\begin{array}{l}\text { Particle } \\
\text { density } \\
\left(\mathrm{kg} \mathrm{m}^{3}\right)\end{array}$ & $810.21 \pm 1.53^{h}$ & $808.13 \pm 1.15^{9}$ & $781.35 \pm 1.97^{\circ}$ & $765.28 \pm 2.11^{b}$ & $805.10 \pm 2.58^{\mathrm{e}}$ & $798.03 \pm 2.17^{d}$ & $808.08 \pm 1.57^{f}$ & $765.11 \pm 2.29^{\mathrm{a}}$ \\
\hline Porosity (\%) & $59.08 \pm 2.56^{\mathrm{a}}$ & $72.61 \pm 2.18^{\mathrm{e}}$ & $77.27 \pm 1.97^{9}$ & $71.77 \pm 2.35^{\mathrm{d}}$ & $73.07 \pm 2.13^{f}$ & $66.66 \pm 2.49^{\circ}$ & $59.27 \pm 1.94^{b}$ & $79.90 \pm 2.24^{h}$ \\
\hline
\end{tabular}

Values are mean of three replicates \pm S.D.; Value with same letter in the same row is not significantly different at $p \leq 0.05$

Table 2: Functional properties of reconstituted cassava dry starch sago

\begin{tabular}{|c|c|c|c|c|c|c|c|c|}
\hline $\begin{array}{l}\text { Physical } \\
\text { properties }\end{array}$ & $\mathrm{T}_{1}$ & $\mathrm{~T}_{2}$ & $\mathrm{~T}_{3}$ & $\mathrm{~T}_{4}$ & $T_{5}$ & $\mathrm{~T}_{6}$ & $T_{7}$ & $T_{8}$ \\
\hline $\begin{array}{l}\text { Swelling } \\
\text { power }\left(g g^{-1}\right)\end{array}$ & $4.12 \pm 0.22^{a}$ & $5.98 \pm 0.18^{9}$ & $5.65 \pm 0.12^{d}$ & $4.96 \pm 0.14^{b}$ & $6.34 \pm 0.16^{h}$ & $5.54 \pm 0.24^{c}$ & $5.92 \pm 0.15^{\dagger}$ & $5.83 \pm 0.13^{\mathrm{e}}$ \\
\hline $\begin{array}{l}\text { Solubility } \\
\text { index }(\%)\end{array}$ & $13.42 \pm 0.20^{\circ}$ & $12.26 \pm 0.16^{b}$ & $16.34 \pm 0.14 f$ & $28.41 \pm 0.16^{h}$ & $13.89 \pm 0.21^{d}$ & $14.63 \pm 0.35^{\circ}$ & $17.55 \pm 0.28^{9}$ & $9.71 \pm 0.23^{a}$ \\
\hline $\begin{array}{l}\text { Cooking } \\
\text { time (min) }\end{array}$ & $9.23 \pm 0.12^{d}$ & $7.41 \pm 0.25^{b}$ & $12.11 \pm 0.15^{h}$ & $10.68 \pm 0.18^{9}$ & $7.57 \pm 0.12^{c}$ & $9.27 \pm 0.21^{\mathrm{e}}$ & $6.12 \pm 0.23^{\mathrm{a}}$ & $10.37 \pm 0.24^{f}$ \\
\hline $\begin{array}{l}\text { Cooking } \\
\text { loss }(\%)\end{array}$ & $7.57 \pm 0.24^{h}$ & $4.28 \pm 0.12^{c}$ & $6.09 \pm 0.46^{9}$ & $4.43 \pm 0.69^{d}$ & $4.62 \pm 0.14^{e}$ & $1.97 \pm 0.14^{b}$ & $5.96 \pm 0.12^{f}$ & $1.73 \pm 0.28^{a}$ \\
\hline $\begin{array}{l}\text { Oil absorption } \\
\left.\text { index }\left(g^{-1}\right)\right)\end{array}$ & $1.35 \pm 0.13^{h}$ & $0.87 \pm 0.18^{c}$ & $0.98 \pm 0.11^{\mathrm{e}}$ & $1.06 \pm 0.14^{\dagger}$ & $0.45 \pm 0.12^{\mathrm{a}}$ & $0.96 \pm 0.12^{d}$ & $0.69 \pm 0.15^{b}$ & $1.34 \pm 0.14^{9}$ \\
\hline
\end{tabular}

Values are mean of three replicates \pm S.D.; Value with same letter in the same row is not significantly different at $p \leq 0.05$

and $T_{4}$. The lowest moisture content $(12.3 \%)$ was noticed in sago prepared with gelatinized starch as binder. The diameter of commercial sago ranged between $1.5 \mathrm{~mm}$ to $4.5 \mathrm{~mm}$. The lowest size of $2.85 \mathrm{~mm}$ was noticed in treatment $T_{8}$, while the highest size of $3.36 \mathrm{~mm}$ was noticed in treatment $T_{5}$. The shape of sago is commercially very important in terms of price and consumer acceptance. Sphericity is an important property to describe the shape of sago. The sphericity of sago made in combination with reconstituted dry starch and binders was lower as compared to wet starch sago $\left(T_{1}\right)$. The peak viscosity of fresh native starches is always higher than those of dry starches and relatively higher fibre content in dry starches (Abera and Rakshit, 2003). During globulation, wet starch is subjected to a process of building up and consolidation, which gives a spherical shape to sago. The high fibre content and low viscosity invariably affected the degree of globulation of sago made using reconstituted dry starch. Moreover, the highest bulk and particle density in treatment $\mathrm{T}_{2}$ and highest porosity (\%) in treatment $T_{8}$ were observed. In general, pregelatinized starch has high binding and water holding capacity due to increased surface area, high porosity, low crystallinity and high roughness (Alebiowu and Itiola, 2002). Thus, these attributes could be responsible for decrease in size and sphericity and increase in porosity of sago made with pre-gelatinized starch as binder.

Data showed that there was a significant difference between swelling power in all treatments (Table 2). The swelling power was high in reconstituted dry starch sago $\left(\mathrm{T}_{2}\right)$ as compared to wet starch sago $\left(T_{1}\right)$. The highest swelling power value $(6.34 \mathrm{~g} / \mathrm{g})$ was found in treatment $T_{5}$, while the lowest value $(4.12 \mathrm{~g} / \mathrm{g})$ was found in control $\left(T_{1}\right)$. The variation in swelling volume could be associated due to decreased hydration of amorphous region (Menon et al., 2015) and increased homogeneity of the crystalline structure (Sasaki and Matsuki, 1998; Jyothi et al., 2011). The solubility index was lower in sago prepared with pre-gelatinzed starch as compared to wet starch as binder (Table 2). The highest 
Table 3: Pasting properties of the reconstituted cassava dry starch sago

\begin{tabular}{|c|c|c|c|c|c|c|c|c|}
\hline sample & $\begin{array}{l}\text { Peak } \\
\text { viscosity } \\
\text { (cP) }\end{array}$ & $\begin{array}{l}\text { Trough } \\
\text { viscosity } \\
\text { (cP) }\end{array}$ & $\begin{array}{l}\text { Breakdown } \\
\text { viscosity } \\
\text { (cP) }\end{array}$ & $\begin{array}{l}\text { Final } \\
\text { viscosity } \\
\text { (cP) }\end{array}$ & $\begin{array}{l}\text { Setback } \\
\text { viscosity } \\
\text { (cP) }\end{array}$ & $\begin{array}{l}\text { Disintegration } \\
\text { rate }(\%)\end{array}$ & $\begin{array}{l}\text { Retrogradation } \\
\text { rate }(\%)\end{array}$ & $\begin{array}{l}\text { Pasting } \\
\text { temperature } \\
\left({ }^{\circ} \mathrm{C}\right)\end{array}$ \\
\hline $\mathrm{T}_{1}$ & $4284 \pm 42^{f}$ & $1931 \pm 23^{f}$ & $2701 \pm 20^{9}$ & $2291 \pm 19^{e}$ & $360 \pm 09^{\mathrm{a}}$ & $63.04 \pm 2.65^{9}$ & $8.40 \pm 1.19^{a}$ & $57.40 \pm 0.02^{b}$ \\
\hline $\mathrm{T}_{2}$ & $3288 \pm 24^{a}$ & $1583 \pm 17^{c}$ & $1357 \pm 19^{a}$ & $2418 \pm 32^{f}$ & $835 \pm 11^{\mathrm{h}}$ & $41.27 \pm 2.13^{\mathrm{a}}$ & $25.39 \pm 1.54^{\mathrm{h}}$ & $69.30 \pm 0.04^{h}$ \\
\hline $\mathrm{T}_{3}$ & $3797 \pm 20^{c}$ & $1472 \pm 20^{\mathrm{a}}$ & $2325 \pm 16^{d}$ & $2078 \pm 24^{c}$ & $606 \pm 08^{9}$ & $61.23 \pm 1.96^{f}$ & $15.95 \pm 2.14^{9}$ & $67.00 \pm 0.01^{9}$ \\
\hline $\mathrm{T}_{4}$ & $4442 \pm 38^{9}$ & $2001 \pm 18^{9}$ & $2441 \pm 14^{\dagger}$ & $2481 \pm 30^{9}$ & $480 \pm 15^{e}$ & $54.95 \pm 2.64^{c}$ & $10.80 \pm 1.93^{\circ}$ & $61.60 \pm 0.03^{\circ}$ \\
\hline $\mathrm{T}_{5}$ & $4608 \pm 41^{\mathrm{h}}$ & $1533 \pm 15^{b}$ & $3075 \pm 17^{\mathrm{h}}$ & $1970 \pm 36^{a}$ & $437 \pm 11^{b}$ & $66.73 \pm 2.95^{\mathrm{h}}$ & $9.48 \pm 1.57^{b}$ & $62.05 \pm 0.06^{d}$ \\
\hline $\mathrm{T}_{6}$ & $3708 \pm 24^{b}$ & $1612 \pm 11^{d}$ & $2096 \pm 20^{c}$ & $2061 \pm 18^{b}$ & $449 \pm 14^{c}$ & $56.52 \pm 1.36^{d}$ & $12.10 \pm 2.18^{\mathrm{e}}$ & $62.20 \pm 0.02^{\mathrm{e}}$ \\
\hline $\mathrm{T}_{7}$ & $4056 \pm 37^{d}$ & $1648 \pm 23^{\mathrm{e}}$ & $2408 \pm 12^{\mathrm{e}}$ & $2175 \pm 21^{d}$ & $527 \pm 17^{f}$ & $59.36 \pm 2.21^{e}$ & $12.99 \pm 2.31^{f}$ & $56.60 \pm 0.05^{\mathrm{a}}$ \\
\hline $\mathrm{T}_{8}$ & $4061 \pm 38^{e}$ & $2264 \pm 18^{h}$ & $1797 \pm 11^{b}$ & $2730 \pm 25^{h}$ & $466 \pm 12^{d}$ & $44.25 \pm 2.59^{b}$ & $11.47 \pm 1.44^{d}$ & $64.65 \pm 0.06^{\dagger}$ \\
\hline
\end{tabular}

Values are mean of three replicates \pm S.D.; Value with same letter in the same row is not significantly different at $p<0.05$

solubility value ( $28.41 \%$ ) was found in $\mathrm{T}_{3}$, while the lowest $(9.71 \%)$ in $\mathrm{T}_{8}$. The competitive hydration abilities of sago in the combination of wet and dry starch might have resulted in high solubility index. The degree of gelatinization of starch directly affects solubility (Harper, 1981). During cooking, the sago absorbs water. The lowest cooking loss $(1.73 \%)$ was observed in case of sago cooked for 10.37 min for treatment $T_{8}$. A reduction in cooking time and cooking loss was reported for reconstituted dry starch sago. It was found that sago made from $95 \%$ reconstituted dry starch, with $5 \%$ pregelatinized starch as binder had only $1.73 \%$ cooking loss, indicating that the heating of sago starch after globulation followed by sun drying accelerated the retrogradation to set the structure of sago (Singh et al., 1989; Singh et al., 2002). The substitution of modified starch for sago production results in discontinuity in the structure of starch, which eventually results in reduction of cooking time (Yadav et al., 2014). All the treatments and their interactions were significant for the oil absorption index of the sago samples. The oil absorption index or uptake by sago made with wet starch $\left(T_{1}\right)$ was highest $(1.35 \%)$, while the sago made in treatment $\mathrm{T}_{8}$ (reconstituted dry starch, $95 \%$ + pre-gelatinized starch, $5 \%$ ) showed lowest oil absorption index. The oil absorption index is affected by lipophillic nature of sago starch granule structure (Babu and Parimalavalli, 2012) and mostly influenced by presence of protein, which contains both hydrophilic and hydrophobic parts (Tharise et al., 2014).

The dynamic moduli involves two parameters viz. storage modulus (G') and loss modulus (G'). In a dynamic oscillation test, the solid behavior of food is characterized by elastic or storage modulus ( $\left.G^{\prime}\right)$ and the liquid behavior by the viscous or loss modulus (G"). Among the treatments, storage modulus was lowest for sago made using wet starch $\left(T_{1}\right)$ due to more fibre content promoting more air spaces in the sago and consequently less compaction in the sago starch granules (Jisha et al., 2009). The storage modulus ( $\left.G^{\prime}\right)$ of the sago made by addition of pregelatinized starch as binder in treatment $T_{8}$ was high (914 Pa). This might be due to adhesion of the pre-gelatinized starch, which enhanced the solid network of sago. The reconstituted dry starch molecules absorb good quantity of water during globulation and form a solid network during roasting (Cui et al., 2014) such swelling was responsible for increase in storage modulus ( $\left.G^{\prime}\right)$ in treatment $T_{5}$ as compared to wet starch sago $\left(T_{1}\right)$. The loss modulus ( $G$ ") was higher than the storage modulus ( $G$ ') of sago made in different treatments. This indicated that the sago gels behaved like a dilute solution, which is also proved by higher phase angle values. This result was in agreement with Chun and Yoo (2006) and Jyothi et al. (2011). The storage and loss modulus increased with increase in frequency for all treatments. The phase angle value was high for control $\left(T_{1}\right)$ at frequency of $10 \mathrm{~Hz}$. However, decrease in phase angle $\left(40^{\circ}\right)$ was noticed when pregelatinized starch was added as a binder in treatment $T_{7}$, with increase in G', indicating better compaction of starch and resulted in solid nature. The lowest complex viscosity was noticed in treatment $\mathrm{T}_{3}$ due to loosened solid network of starch matrix.

Sago made in a combination of wet and reconstituted dry starch showed the significant increase in peak viscosity and pasting temperature (Table 3 ). The highest peak viscosity of sago was noticed for treatment $T_{5}$ due to increase in granule rigidity and resistance to shear (Jacobs et al., 1995). Peak viscosity of sago increased in the following order: $T_{5}>T_{1}>T_{7}$. Sago made in $T_{2}$ showed lowest peak (3288 cP), breakdown (1357 cP) and highest set back viscosity ( $835 \mathrm{cP})$. The decrease in setback viscosity indicates lowering of retrogradation rate and pasting temperature of sago paste (Table 3). There was a significant difference in disintegration rate $(\%)$ of sago in all the treatments. The disintegration rate of sago paste increased in the following order: $T_{5}>T_{1}>T_{2}$. However, the lowest disintegration rate was noticed in treatment $\mathrm{T}_{2}(41.27 \%)$ due to formation of cohesive network. This is also evident by lower value of peak viscosity. A positive correlation was obtained between the peak viscosity and swelling power for disintegration rate (\%) of sago paste. Retrogradation is the process of realignment of amylose and amylopectin molecules structure after gelatinization. The increase in pasting temperature of sago could be due to strengthening of glycosidic bonds, which requires higher temperature to gelatinize starch granules. Usually, starch retrogradation rate decreases with 
increasing moisture content. Thus, high moisture content in wet starch sago $\left(T_{1}\right)$ led to lower retrogradation rate. Sago prepared with reconstituted dry starch (75\%) and wet starch (25\%) showed a size and shape as similar to that of sago made from wet starch. Reconstituted dry starch sago showed higher swelling power, higher solubility and lower oil absorption index and lower cooking loss in comparison to wet starch sago. The storage and loss modulus increased with increase in frequency for sago made from reconstituted dry as well as wet starch. The increase in peak viscosity of reconstituted dry starch sago showed decrease in retrogradation rate and pasting temperature. These findings would be useful for production of sago and sago based functional foods using reconstituted cassava based dry starch.

\section{Acknowledgment}

The authors are thankful to the Director, ICAR-CTCRI, Trivandrum for providing the research facilities to conduct the study.

\section{References}

AACC:Approved Methods of the AACC International, Methods 66-50.01. The AssociationAACC, $10^{\text {th }}$ Edition (2000).

Abera, S. and S.K. Rakshit: Processing technology comparison of physico-chemical and functional properties of cassava starch extracted from fresh root and dry chips. Starch-Stärke, 55, 287296 (2003).

Alebiowu, G. and O. A. Itiola: Compressional characteristics of native and pregelatinized forms of sorghum, plantain, and corn starches and the mechanical properties of their tablets. Drug Dev. Ind. Pharm., 28, 663-672 (2002).

AOAC: Official Methods of Analysis. Association of Official Analytical Chemists. $16^{\text {th }}$ Edn. (1999).

Babu, A.S. and R. Parimalavalli: Functional and chemical properties of starch isolated from tubers. Int. J. Agricul. Food Sci., 2, 77-80 (2012).

Balagopalan, C., G. Padmaja, S.K. Nanda and S.N. Moorthy: Cassava in Food, Feed and Industry. CRC Press, Boca Raton, USA., pp. 159-188 (1988)

Betancur, D.A., L.A.C. Ancona, R.I. Guerrero, G. Camelo Matos and D. Ortiz: Physico-chemical and functional characterization of baby lima bean (Phaseolus lunatus) starch. Starch-Stärke, 53, 219-226 (2001).

Bureau of Indian Standard (BIS): Requirements for Sago. IS:899, pp. 1012 (1971).

Chun, S.Y. and B. Yoo: Steady and dynamic shear rheological properties of sweet potato flour dispersions. European Food Res. Technol., 223, 313-319 (2006).

Cui, M., L. Fang, H. Zhou and H. Yang: Effects of amino acids on the physio-chemical properties of potato starch. Food Chem., 151, 162-167 (2014).

Debbous, A. and C. Doctkott: Effect of process variables on spaghetti quality. Cereal Chem., 73, 673-677 (1999).

Ding, Q.B., P. Ainsworth, A. Plunkett, G. Tucker and H. Marson: The effect of extrusion conditions on the functional and physical properties of wheat-based expanded snacks. J. Food Engin., 73, 142-148 (2006).

Ferry, J.D: Viscoelastic Properties of Polymers. $3^{\text {rd }}$ Edn., Wiley (1980).

George, M., S.N. Moorthy and G. Padmaja: Biochemical changes in cassava tuber during fermentation and its effect on extracted starch and residue. J. Sci. Food Agricul., 69, 367-371 (1995).

Harper, J.M: Extrusion of Foods. CRC Press, Vol 1 and 2 (1981).
Jacobs, H., R.C. Eerlingen, W. Clauwaert and J.A. Delcour: Influence of annealing on the pasting properties of starches from varying botanical sources. Cereal Chem., 72, 480-487 (1995).

Jisha, S., G. Padmaja, S.N. Moorthy and M.S. Sajeev: Textural and rheological properties of whey protein concentrate fortified baked products from cassava based composite flours. J. Food Sci. Technol. (Mysore), 46, 532-537 (2009).

Jyothi, A.N., K.S. Kiran, B. Wilson, S.N. Moorthy and B. Nambisan: Wet storage of cassava starch: Use of sodium metabisulphite and acetic acid and the effect on starch properties. Starch-Stärke, 59, 141-148 (2007).

Jyothi, A.N., M.S. Sajeev and J. Sreekumar: Hydrothermal modifications of tropical tuber starches-Effect of ANN on the physico-chemical, rheological and gelatinization characteristics. Starch-Stärke, 63, 536-549 (2011).

Krishnakumar, T. and M.S. Sajeev: Effect of ultrasound treatment on physicochemical and functional properties of cassava starch. Int. J. Curr. Microbiol. App. Sci., 7, 3122-3135 (2018).

Krishnakumar, T. and M.S. Sajeev: Response surface optimization of bath type ultrasound-assisted extraction (UAE) of native starch from fresh cassava tubers. Advances in Research, 12, 1-13 (2017).

Liadakis, G.N., A. Floridis, A.C. Tzi and V. Oreopoulou: Protein isolates with reduced gossypol content from screw-pressed cottonseed meal. J. Agric. Food Chem., 41, 918-922 (1993).

Menon, R., G. Padmaja and M.S. Sajeev: Ultrastructural and starch digestibility characteristics of sweet potato spaghetti: Effects of edible gums and fibers. Int. J. Food Propert., 18, 1231-1247 (2015).

Mohsenin, N.N.: Physical properties of plant and animal materials. Gordon and Breach, $581.1 \mathrm{M} 64$ (1986).

Nanda, S.K. and G.T. Kurup: Processing and process equipments for tuber crops. In: Advances in Horticulture: Tuber Crops (Eds.: K. L. Chadha and G. G. Nayar). Malhotra Publishing House, Vol. 8, pp. 703-714 (1994).

Sajeev, M.S. and C. Balagopalan: Performance evaluation of multipurpose mobile starch extraction plant for small scale processing of tuber crops. J. Root Crops, 31, 106-110 (2005).

Sajeev, M.S., S.K. Nanda and J.T. Sheriff: An efficient blade type rasper for cassava starch extraction. J. Root Crops, 38, 151-156 (2012).

Sasaki, T. and J. Matsuki: Effect of wheat structure on swelling power. Cereal Chem., 75, 525-529 (1998).

Sheriif, J.T., S.K. Nanda and M.S. Sajeev: Current status of cassava processing Industries in South India. Technical Bulletin No. 42. Central Tuber Crops Research institute, Sreekariyam, Thiruvananthapuram, Kerala, India (2005).

Singh, U., W. Voraputhaporn, P.V. Rao and R. Jambunathan: Physicochemical characteristics of pigeon pea and mung bean starches and their noodle quality. J. Food. Sci., 54, 1293-1297 (1989).

Singh, N., J. Singh and N.S. Sodhi: Morphological, thermal, rheological and noodle-making properties of potato and corn starch. J. Sci. FoodAgric., 82, 1376-1383 (2002).

Tharise, N., E. Julianti and M. Nurminah: Evaluation of physico-chemical and functional properties of composite flour from cassava, rice, potato, soybean and xanthan gum as alternative of wheat flour. Int. Food Res. J., 21, 1641-1649 (2014).

Vijakumari Asha., A.N. Jyothi, G. Padmaja, J.T. Sheriff and K. Jeevaratnam: Preparation and characterization of a low calorie cassava pearl (Sago) from physically modified cassava starch. Trends in Carbohyd. Res., 6, 33-40 (2014).

Yadav, B.S., R.B. Yadav, M. Kumar and B.S. Khatkar: Studies on suitability of wheat flour blends with sweet potato, colocasia and water chestnut flours for noodle making. LWT- Food Sci Technol., 57, 352-358 (2014). 